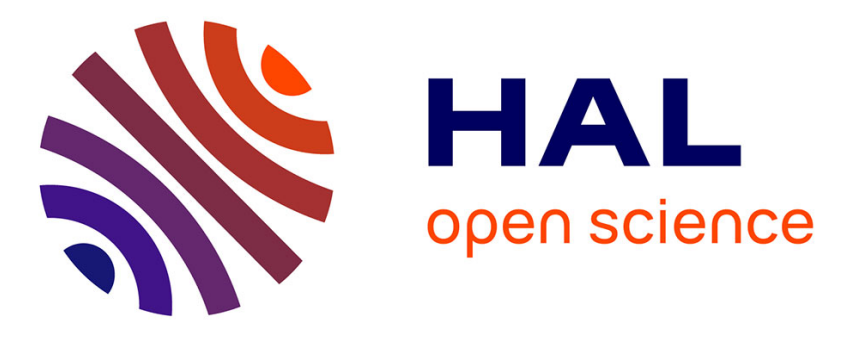

\title{
Correction models for intergenotypic competition in winter wheat
}

Vincent Foucteau, Philippe Brabant, Hervé Monod, Olivier David, Isabelle Goldringer

\section{- To cite this version:}

Vincent Foucteau, Philippe Brabant, Hervé Monod, Olivier David, Isabelle Goldringer. Correction models for intergenotypic competition in winter wheat. Agronomie, 2000, 20 (8), pp.943-953. 10.1051/agro:2000170 . hal-00886096

\section{HAL Id: hal-00886096 https://hal.science/hal-00886096}

Submitted on 1 Jan 2000

HAL is a multi-disciplinary open access archive for the deposit and dissemination of scientific research documents, whether they are published or not. The documents may come from teaching and research institutions in France or abroad, or from public or private research centers.
L'archive ouverte pluridisciplinaire HAL, est destinée au dépôt et à la diffusion de documents scientifiques de niveau recherche, publiés ou non, émanant des établissements d'enseignement et de recherche français ou étrangers, des laboratoires publics ou privés. 


\title{
Correction models for intergenotypic competition in winter wheat
}

\author{
Vincent Foucteau ${ }^{\mathrm{a} *}$, Philippe Brabant ${ }^{\mathrm{a}, \mathrm{b}}$, Hervé MONOD $^{\mathrm{c}}$, \\ Olivier DAVID ${ }^{\mathrm{c}}$, Isabelle GOLDRINGER ${ }^{\mathrm{a}}$ \\ aStation de Génétique Végétale, Ferme du Moulon, 91190 Gif-sur-Yvette, France \\ bINA-PG, 16 rue Claude Bernard, 75005 Paris, France \\ 'INRA, Unité de Biométrie, 78352 Jouy-en-Josas, France
}

(Received 30 June 2000; accepted 6 September 2000)

\begin{abstract}
Single-row plots (SRP) are often used in early generation selection. For wheat, in such trials, it has already been demonstrated that inter-plot competition leads to highly biased estimations of grain yield. An experiment including one SRP trial and one reference 6-row-plot trial were conducted over two consecutive years in order to compare two statistical models for correcting competition effects. The neighbourhood covariate model relying on plant height proved to be more efficient than the more general producer-competitor model. It provided significant improvement in yield estimation, slightly greater using height measured at heading than using final height as covariate. Moreover, relative efficiency of selection in SRP when corrected for competition effects always reached about $85 \%$, whatever the intensity of competition. The neighbouring covariate model based on plant height should be used for routine analysis of singlerow-plot trials.
\end{abstract}

intergenotypic competition / wheat (Triticum aestivum L.) / early generation selection / correction models

Résumé - Modèles de correction de la compétition inter-génotypique chez le blé. Les parcelles monorang sont souvent utilisées dans les schémas de sélection précoce. Dans de tels dispositifs, il a été montré que la compétition entre parcelles adjacentes introduisait un biais dans l'évaluation du rendement. Afin de comparer l'efficacité de plusieurs modèles pour corriger les effets de la compétition, une expérimentation comprenant un essai constitué de parcelles monorang et un essai de référence constitué de parcelles de 6 rangs a été conduite deux années consécutives. Le modèle incluant la covariable de voisinage utilisant la hauteur des plantes s'est révélé plus efficace que le modèle producteurcompétiteur pour corriger le biais introduit par la compétition dans l'évaluation du rendement en parcelles monorang. La correction effectuée par la covariable est faiblement mais significativement meilleure dans le cas où la hauteur est

Communicated by Christian Huyghe (Lusignan, France)

* Correspondence and reprints

Vincent.Foucteau@jouy.inra.fr

Present address: INRA, Unité de Biométrie, 78352 Jouy-en-Josas, France. 
mesurée à l'épiaison qu'à la récolte. D'autre part, l'efficacité relative de la sélection en parcelles monorang, une fois corrigés les effets de la compétition, atteint toujours $85 \%$, quelle que soit l'intensité de la compétition. La covariable de voisinage utilisant la hauteur des plantes est proposée pour l'analyse en routine des dispositifs d'essais en parcelles monorang.

competition intergénotypique / blé (Triticum aestivum L.) / sélection précoce / modèles de correction

\section{Introduction}

For many cereal crops, competition between different genotypes strongly modifies their morphological as well as their productivity traits with regard to the monoculture condition $[2,17]$. Interactions between genotypes may occur between adjacent plots; then their importance is all the greater as plots have a high ratio of perimeter over surface. For cereal crops, limitation of seed per inbred line at the first generations of selection combined with very high number of genotypes to be tested often implies the use of single-row plots for yield evaluation. In these trials, interplot competition may lead to biased estimations of yield performances [9] and particularly to the overestimation of the value of aggressive genotypes. Several authors have noted very low or even no correlations between yields of genotypes in singlerow plots and their yield in larger plots due to competition $[6,10,15]$.

The accurate assessment of yield performance of inbred lines at early stages of a breeding programme is crucial for the detection of genotypes likely to become future registered varieties. Different models have been developed for correcting competition effects [4]. When competition can be associated with any plant character, one (or more) covariate equal to the difference for the character between the value of the plot and the mean of the adjacent plots can be introduced in the model [14]. If the yields of adjacent plots are negatively correlated, an autoregressive model may be successfully fitted [12]. The producer-competitor model is a general method, in case no knowledge concerning the mechanisms of competition is available $[1,13,20]$. In a previous paper, the three kinds of model were fitted to a set of wheat yield data displaying strong competition effects [10]. The authors found that the best fit could be obtained with a single covariate model. However, the difference between the covariate model and the producer-competitor model was slight and had not been statistically tested.

The aim of this paper is to identify, from the neighbourhood covariates approach and the producer-competitor model, the most efficient correction model for improving the prediction of the monoculture yield from the single-row plot yield estimated with few replications, and to determine the most relevant trait to be used as a covariate for wheat. For this purpose, we compare two competition models on a set of data derived from two experiments, one of which displayed a relatively low level of competition and the other displayed a high level of competition.

\section{Materials and methods}

\subsection{Experimental procedures}

Plant material consisted of 40 inbred lines of winter wheat derived by haplodiploidization from a broad-based population obtained after the random crossing of 80 families selected at the third cycle of a recurrent selection scheme. The lines were grown in two different trials: a single-row-plot trial (SRP) and a reference 6-row-plot trial (6RP). The SRP trial included a randomised complete block design with four replicates in which plots were $1.50 \mathrm{~m}$ long and $25 \mathrm{~cm}$ apart. Thirty seeds were sown in each plot. The four replicates were placed end to end (the last plot of block $k$ next to the first plot of block $k+1$ ). The SRP trials were partially neighbour-balanced: a given genotype never had the same neighbour twice over the 4 replicates. 
Guard plots were sown next to the first plot of block 1 and the last plot of block 4 . The reference trial consisted of a two-replication randomised complete block design of $4 \mathrm{~m}$ long 6-row-plots. The sowing density was 250 seeds $\cdot \mathrm{m}^{-2}$. Competition has sometimes been found in 6-rowplot trials within heterogeneous samples of triticale [14] or wheat genotypes [16]. Yet we assumed here that competition effects in the 6RP trial are negligible as regard to those in the SRP trial, as it was also reported by Brabant et al. [5] and Goldringer et al. [10]. This will be checked from the analysis of the 6RP data. The experiment was repeated two years consecutively (1992-1993 and 1993-1994) but only 9 genotypes were common in both experiments. The experiments were conducted in homogeneous and deep silts of the "Le Moulon" plateau (Paris basin).

The number of plants was recorded at the end of winter in each plot of the SRP trial to control density differences, which may be important in such trials. The beginning of active stem elongation was recorded as it is an important agronomic stage that corresponds to a marked change in plant growth. It was defined as the time when the average distance (d) between the summit of the apex and the base of the lower embryonic internode reached $1 \mathrm{~cm}$. This time $(\mathrm{E} 1 \mathrm{CM})$ was determined from interpolation of the curve relating $d$ to thermal time. The measure of E1CM is destructive and hence was performed in one of the two replications of the 6RP trial. The very high heritability of this trait allowed us to associate the measurement to the four single-row plots containing the same genotype. The other measurements were recorded in each plot. Heading date (HEAD) was expressed in thermal time from sowing. Earliness traits (HEAD and E1CM) introduce phenology differences that can lead to a decisive occupation of soil or space and hence may explain competition ability. Plant height was measured at heading $(\mathrm{HH})$ and at maturity $(\mathrm{HM})$ in $\mathrm{cm}$. These two traits are likely to explain competition for light. Height at heading time was only recorded the first year. The agromorphological traits (E1CM, HEAD, HH and HM) have been chosen to be distributed all over the wheat development cycle. Grain yield, GY $\left(\mathrm{g} \cdot \mathrm{m}^{-2}\right)$, was recorded from the harvest of the whole plots in both trials. Yield estimated in SRP often gives unrealistic values when divided by the true row area. So, SRP yield estimation has been multiplied by the appropriate coefficient so that the overall SRP mean was equal to the overall 6RP mean.

\subsection{Statistical methods}

Let $d(j, k)$ denote the genotype on the $j$ th plot $(j=$ $1 \ldots I$, where $I=40$ is the number of genotypes) of block $k(k=1 \ldots K$, with $K=4$ in the SRP trial and $K=2$ in the $6 \mathrm{RP}$ trial). In the two-factor model of analysis of variance, ignoring competition, $Y_{j k}=\mu$ $+g_{d(j, k)}+b l_{k}+E_{j k}$, the response for the trait $\mathrm{Y}$ on the $j$ th plot of block $k$, was split up into the sum of the overall mean, $\mu$, a fixed effect for the genotype grown on this plot, $g_{d(j, k)}$, a fixed effect for the block $k, b l_{k}$, and a random error effect, $E_{j k}$. This model was fitted to all traits measured in both trials. We also estimated variance components for the genetic effect, considered as random, and for the error [18, p. 244]; they are denoted by $\hat{V}_{G}$ and $\hat{V}_{E}$ respectively. Broad sense heritability at the level of the trial was estimated by

$$
\hat{h}_{B S}^{2}=\frac{\hat{V}_{G}}{\hat{V}_{G}+\frac{\hat{V}_{E}}{K}} .
$$

Genetic correlation coefficients $\rho_{G}$ between traits were estimated from the two-factor model. Approximate standard errors on $\hat{\rho}_{G}$ were derived using the formula given by Scheinberg [19] and Becker [3]. As the distribution of $\rho_{G}$ is unknown, we arbitrarily considered $\hat{\rho}_{G}$ as significant when its absolute value was greater than twice its standard error.

Two models were tested in order to correct for interplot competition effects. The first model included a distance-one neighbouring covariate equal to the difference in height or earliness between the plot and its neighbours' mean. Hence, the response $\mathrm{Y}$ was described as:

$$
Y_{j k}=\mu+g_{d(j, k)}+b l_{k}+\beta\left(h_{j k}-\frac{1}{2}\left(h_{j-1, k}+h_{j+1, k}\right)\right)+E_{j k}
$$


where $h_{j, k}$ is the associate trait measured on the $j$ th plot of block $k$ and $\beta$ is the regression coefficient for the covariate. Four distance-one neighbouring covariates (d1E1CM, d1HEAD, d1HH and d1HM) were computed from the four agromorphological traits (respectively E1CM, HEAD, HH and HM). A distance-2 neighbouring covariate defined as $h_{j k}-\frac{1}{2}\left(h_{j-2, k}+h_{j+2, k}\right)$ was computed for height at heading (d2HH) and height at maturity (d2HM). The associate trait measured on the guard plots was used in place of $h_{0,1}$ and $h_{I+1, K}$ (as well as $h_{-1,1}$ and $h_{I+2, K}$ for the distance-2 neighbouring covariates). Regression coefficients for height covariates were estimated and changed into percentage of mean yield per $\mathrm{cm}$ so that they could be compared over the two seasons and with estimations from other studies. Combination of the different covariates that had been previously found significant alone were also tested. The genotypic value for a trait corrected from competition effects was estimated with adjusted $\hat{g}_{i}$.

The producer-competitor model $[1,13,20]$ partitions the response for the trait $\mathrm{Y}$ on the $j$ th plot of block $k$, into a producer effect due to the genotype of this plot $p r_{d(j, k)}$, and two competitor effects related to the genotypes of the two neighbouring plots, $c p_{d(j-1, k)}$ and $c p_{d(j+1, k)}$ :

$$
Y_{j k}=\mu+b l_{k}+p r_{d(j, k)}+c p_{d(j-1, k)}+c p_{d(j+1, k)}+E_{j k} .
$$

For the first plot of block 1 and the last plot of block $K$, only one competitor effect was considered, $c p_{d(2,1)}$ and $c p_{d(I-1, K)}$, respectively.

Genetic parameters $p r_{i}$ and $c p_{i}$ were combined to produce a corrected estimation of the genotypic value for each trait, $\mathrm{g}_{\mathrm{i}}^{*}=p r_{i}+2 c p_{i}$, which is the expected value of genotype $i$ in competition with itself.

The correlations between SRP genotypic means and 6RP genotypic means were compared to the expected correlations in the absence of competition, $r_{0}=\sqrt{\hat{h}_{B S, S R P}^{2} \cdot \hat{h}_{B S, 6 R P}^{2}}$, where $\tilde{h}_{B S, S R P}^{2}$ and $\hat{h}_{B S, 6 R P}^{2}$ are respectively the broad sense heritabilities estimated at the trial level in SRP and 6RP.
The efficiency of these two models in correcting the bias introduced by competition was judged in comparison to the two-factor model. Two main criteria have been investigated: (i) the residual mean square decrease in the analysis of variance; this criterion, internally derived from the data of the SRP trial, reflects the model adjustment to the data; (ii) the correlation between corrected SRP genotypic means and 6RP genotypic means. It was also expressed as the relative selection efficiency, i.e. the ratio of the expected genetic gain in 6RP when selection is based on the SRP performance to the expected response when selection is applied directly to the 6RP trial. The relative selection efficiency was estimated by $r / \hat{h}_{B S, 6 R P}^{2}$, where $r$ is the correlation coefficient between the genotypic means of the two trials and $\hat{h}_{B S, 6 R P}^{2}$ the broad sense heritability in the 6RP trial [15].

Correlation coefficients between 6RP genetic means and SRP genetic values obtained with the different models described above (the two-factor analysis of variance model, neighbouring covariate models or the producer-competitor model) were statistically compared using the bootstrap resampling technique [8]. Let $r_{1}$ be the correlation coefficient between SRP genetic values estimated from model 1 and 6RP genetic means. Let $r_{2}$ be the correlation coefficient between SRP genetic values estimated from model 2 and 6RP genetic means. A bootstrap sample was obtained by drawing 40 genotypes at random and with replacement from the 40 tested genotypes, together with their SRP genetic values estimated from model 1 and model 2, and their 6RP genetic means. From this sample, a new value of $r_{2}-r_{1}$ was calculated. The bootstrap probability distribution of $r_{2}-r_{1}$ was obtained by repeating this procedure a large number of times (we used 10000 bootstrap samples for each comparison). Then the hypothesis " $H_{A}: \rho_{2}$ > $\rho_{1}$ " has been tested against the hypothesis " $H_{0}: \rho_{2}$ $=\rho_{1}$ " with $\rho_{1}$ and $\rho_{2}$ the expected values of $r_{1}$ and $r_{2}$. The models used to correct for interplot competition were first compared to the initial two-factor model. Then, models which were significantly better than the two-factor model $\left(H_{A}\right.$ accepted) were compared. 


\section{Results}

The covariate computed with the number of plants recorded at the end of winter in SRP plots was not significant when introduced in the analysis of variance model of SRP grain yield, indicating that density differences between SRP plots had not modified yield expression.

\subsection{Evidence of intergenotypic competition}

Intergenotypic competition has been shown to lead to an overestimation of genetic variability [5, 10]. This was found again in both experiments: genetic variation coefficients were much larger in the SRP trial than in the 6RP trial (Tab. I). The increase in genetic variation was higher in 1993 than in 1994, suggesting that competition phenomena were stronger in 1993 than in 1994. Environmental variation coefficients were also larger in the SRP trial, indicating that a better control of experimental conditions was obtained with large plots. Generally speaking, the characteristics of the experiment were more favourable in 1994 (higher mean, lower $\mathrm{CV}_{\mathrm{E}}$ and higher yield heritability) than in 1993 due to severe weather conditions, especially during heading and flowering periods in 1993.

The correlations between height and yield were different among trials (Tab. II). Whereas height was positively linked to yield in SRP, the correlation was not significantly different from zero in the reference trial. Positive correlation between plant height and yield in SRP trials had already been found by Hamblin \& Donald [11] and Goldringer et al. [10]. Height is highly involved in betweenplot competition which tends to favour tall genotypes in SRP trials. Neither heading date nor E1CM showed such differences in correlations.

The correlation between genotypic mean yield in SRP and 6RP was rather low with regard to the expected correlation in the absence of competition $r_{0}\left(0.44\right.$ with $r_{0}=0.83$ in 1993 and 0.73 with $r_{0}=$ 0.90 in 1994), indicating that competition disturbed yield expression. This also confirmed that
Table I. Phenotypic mean, genetic and environmental variation coefficients and estimated broad sense heritability at the level of the trial $\hat{h}_{B S}^{2}=\frac{\hat{V}_{G}}{\hat{V}_{G}+\frac{\hat{V}_{E}}{K}}$ for grain yield $\left(\mathrm{g} \cdot \mathrm{m}^{-2}\right)$ in single-row-plot trial (SRP) and 6row-plot trial (6RP).

\begin{tabular}{lccc}
\hline & & 1993 & 1994 \\
\hline Mean ${ }^{1}$ & & 506 & 887 \\
\hline $\mathrm{VC}_{\mathrm{G}}(\%)$ & $\mathrm{SRP}$ & 37.1 & 20.5 \\
& 6RP & 13.4 & 12.7 \\
\hline $\mathrm{VC}_{\mathrm{E}}(\%)$ & $\mathrm{SRP}$ & 23.5 & 15.7 \\
& 6RP & 10.7 & 4.9 \\
\hline$\hat{h}_{B S}^{2}$ & SRP & 0.91 & 0.87 \\
& 6RP & 0.75 & 0.93
\end{tabular}

${ }^{1}$ The harvested grain weight per plot in SRP trial has been multiplied by the appropriate coefficient so that the SRP means were equal to the $6 \mathrm{RP}$ means.

Table II. Phenotypic (1) and genetic (2) correlations between three agromorphological traits (E1CM, stem elongation beginning date, HEAD, heading date and $\mathrm{HM}$, height measured at maturity) and yield (GY), in single-row-plot trial (SRP) and 6-row-plot trial (6RP).

\begin{tabular}{llll}
\hline & & \multicolumn{2}{c}{ GY } \\
& & 1993 & 1994 \\
\hline E1CM $^{1}$ & SRP & $\underline{-0.46}$ & $\underline{-0.52}$ \\
& 6RP & $\underline{-0.28}$ \\
HEAD $^{2}$ & SRP & $\underline{-0.63}$ & $\underline{-0.35}$ \\
& 6RP & $\underline{-0.43}$ \\
$\mathrm{HM}^{2}$ & SRP & $\underline{0.75}$ & $\underline{0.60}$ \\
& 6RP & -0.24 & 0.14
\end{tabular}

${ }^{1}$ Phenotypic correlation between the E1CM value and the phenotypic mean for GY. Coefficients significantly different from zero at the $5 \%$ level are underlined.

${ }^{2}$ Genetic correlations. Underlined values correspond to coefficients greater in absolute value than twice their standard error (see text for details). 
competition effects were stronger in 1993. Relative selection efficiency was 59\% in 1993 and $78 \%$ in 1994.

Genotypic correlations between grain yield and height at maturity in the 6RP trial were not significantly different from zero. Moreover, the neighbouring covariate based on height differences was not significant when introduced in the analysis of variance model for grain yield in 6RP. Hence no evidence of competition related to plant height could be found in the 6RP trial. Therefore we consider the use of the 6RP trial as a reference to be acceptable.

\subsection{Correction of single-row-plot yield estimation}

All the distance-one neighbouring covariates, except d1E1CM, led to a significant reduction of the residual mean square when introduced in the analysis of variance model of grain yield (Tab. III). The two height covariates, d1HH and d1HM, were the most efficient. Residual mean square was reduced by $23 \%$ in 1993 and $12 \%$ in 1994 compared to the initial two-factor model. After adjustment for competition with height covariates, the correlation between yield estimations in the two

Table III. Comparison between different competition models fitted to yield $\left(\mathrm{g} \cdot \mathrm{m}^{-2}\right)$ estimated in the single-row-plot trial. As in the text, d1HEAD, d1HH and d1HM are the distance-one neighbouring covariates computed respectively with heading date, height at heading and height at maturity; $\mathrm{d} 2 \mathrm{HH}$ and $\mathrm{d} 2 \mathrm{HM}$ are the distance-2 neighbouring covariates computed respectively with height at heading and height at maturity.

\begin{tabular}{|c|c|c|c|c|}
\hline Model & df & $\begin{array}{l}\text { Residual } \\
\text { mean square }{ }^{1}\end{array}$ & $\begin{array}{l}\text { Phenotypic } \\
\text { correlation } \\
\text { with } 6 \mathrm{RP}^{2}\end{array}$ & $\begin{array}{l}\text { Relative } \\
\text { selection } \\
\text { efficiency }\end{array}$ \\
\hline
\end{tabular}

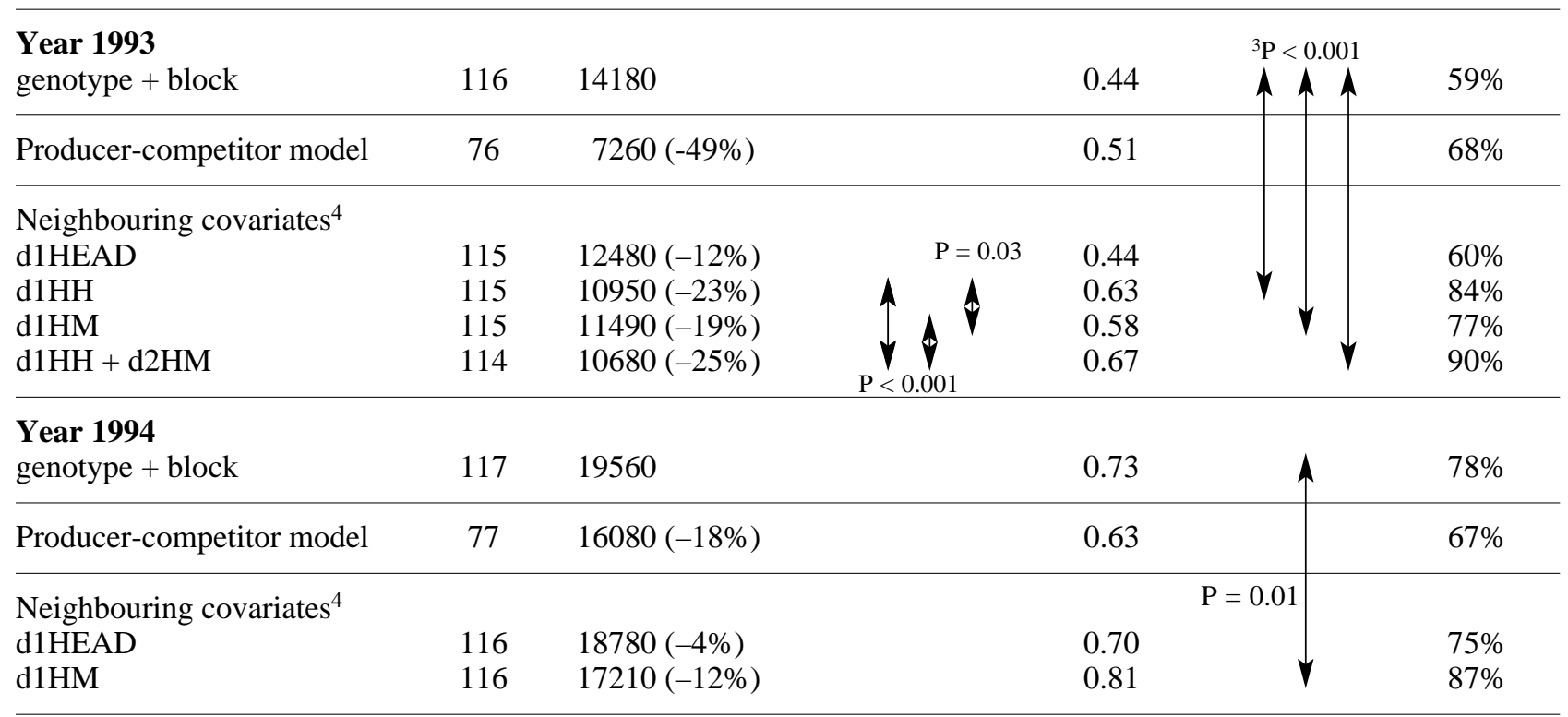

\footnotetext{
${ }^{1}$ In brackets, the residual mean square decrease compared with the genotype + block model.

2 Phenotypic correlation between SRP yield corrected with the different models and 6RP yield.

${ }^{3} \mathrm{P}$ is the probability given by the bootstrap test of the hypothesis " $\mathrm{H}_{0}: \rho_{2}=\rho_{1}$ " against the hypothesis " $\mathrm{H}_{\mathrm{A}}: \rho_{2}>\rho_{1}$ " where $\rho_{1}$ and $\rho_{2}$ are the correlations pointed out by the arrows.

${ }^{4}$ Only significant covariates (at the 5\% level) are mentionned.
} 
trials increased significantly $(P<0.001)$ from 0.44 to 0.63 in 1993 and from 0.73 to 0.81 in 1994 . The efficiency of height covariates in adjustment for competition in wheat had already been observed $[10,14]$. Our results showed that the covariate using height at heading time (only measured in $1993)$ led to a slightly, but significantly $(P=0.03)$ better correction than the covariate for height at maturity ( $r=0.63$ instead of 0.58 ). Indeed, the former trait contains an additional earliness information, since height at heading was more strongly correlated with E1CM and HEAD (phenotypic correlation coefficients were respectively -0.35 and $-0.66)$ than height measured at maturity $(-0.21$ and -0.42 ). A $2 \mathrm{~cm}$ difference in height between a plot and its neighbours led to a yield deviation of more than $10 \mathrm{~g} \cdot \mathrm{m}^{-2}(1.2 \%$ of mean yield per $\mathrm{cm}$ in 1993 , $0.56 \%$ in 1994) (Tab. IV). This result is consistent with the estimate obtained by Goldringer et al. [10] who found a value slightly over $1 \%$.

We used the distance-2 (d2) neighbouring covariates based on $\mathrm{HH}(\mathrm{d} 2 \mathrm{HH})$ and $\mathrm{HM}(\mathrm{d} 2 \mathrm{HM})$ in order to test whether the effects of competition might be found between genotypes grown 2 rows apart or not. The $\mathrm{d} 2 \mathrm{HH}$ and $\mathrm{d} 2 \mathrm{HM}$ covariates were introduced in the analysis of variance model in addition to d1HH or d1HM. The only combination of covariates to be significant was $\mathrm{d} 1 \mathrm{HH}+\mathrm{d} 2 \mathrm{HM}$ in 1993. The correlation between adjusted yield in SRP and yield in 6RP was significantly increased from 0.63 with $\mathrm{d} 1 \mathrm{HH}$ as single covariate to 0.67 . Estimates of the regression coefficients were $5.29 \mathrm{~g} \cdot \mathrm{m}^{-2} \cdot \mathrm{cm}^{-1}$ for $\mathrm{d} 1 \mathrm{HH}$ and 2.22 for $\mathrm{d} 2 \mathrm{HM}$. A positive regression coefficient for $\mathrm{d} 2 \mathrm{HM}$ indicates that competition related to plant height can occur between genotypes grown 2 rows apart when competition is strong. As d2HH was not significant, it is likely that competition affects genotypes of more distant rows mainly at the ultimate stage of plant development.

Including the covariate calculated with heading date (d1HEAD) in addition to d1HH or d1HM, very little decreased the residual mean square. But none of the two-covariate combinations improved the correlation to the 6RP trial compared to the most efficient single covariate, probably because
Table IV. Estimates of regression coefficients for distance-one neigbouring covariate computed with height at heading $\left(\beta_{\mathrm{d} 1 \mathrm{HH}}\right)$ and height at maturity $\left(\beta_{\mathrm{d} 1 \mathrm{HM}}\right)$.

\begin{tabular}{|c|c|c|}
\hline & 1993 & 1994 \\
\hline$\beta_{\mathrm{d} 1 \mathrm{HM}}\left(\mathrm{g} \cdot \mathrm{m}^{-2} \cdot \mathrm{cm}^{-1}\right)[$ s.e.] & $6.08[0.11]$ & $4.97[0.12]$ \\
\hline$\beta_{\mathrm{d} 1 \mathrm{HH}}\left(\%\right.$ of mean yield $\left.\mathrm{cm}^{-1}\right)$ & $\begin{array}{l}5.41[0.09] \\
1.20\end{array}$ & 0.56 \\
\hline$\beta_{\mathrm{d} 1 \mathrm{HH}}$ & 1.07 & \\
\hline
\end{tabular}

covariates were correlated and the major part of competition was explained by height.

The producer-competitor model led to a great improvement in the fit to the data: the residual mean square was decreased by $49 \%$ in 1993 and $18 \%$ in 1994 compared with the initial two-factor model (Tab. III). However, the correlation to the reference trial was not significantly improved in any year.

\section{Discussion}

In a previous experiment, Goldringer et al. [10] found the correlation between SRP and 6RP genotypic mean yield not different from zero and concluded in the complete inefficiency of selection based on uncorrected SRP means. In the present study, the higher correlation values were estimated on a sample of random doubled haploid lines, displaying a greater genetic variation: genetic variation coefficients calculated on 6RP were about $13 \%$ (Tab. I) while it was only $8 \%$ in the previous study [10]. This wider genetic variation explains the relative efficiency of SRP in spite of the bias introduced by competition. When differences between genotypes are smaller, as was the case in the previous experiment, this bias due to competition makes the prediction of genotypic values less reliable. Yet our results showed that it is worthwhile correcting yield estimation for competition effects.

The best fit to the SRP data was obtained with the producer-competitor model. However, models 
including height neighbouring covariates were the most efficient to make SRP yield estimates closer to the reference value (6RP estimate). In both experiments, whatever the intensity of the competition, the introduction of a height covariate in the analysis of variance model always provided a very satisfactory level of relative selection efficiency (around 85\%, Tab. III). Even if the producer-competitor model was more general than those with covariates, it was found less efficient (Tab. III).

One reason was the imprecision of the estimators of producer and competitor effects due to the large number of genotypes (and hence the large number of parameters) compared to the low number of replications.

Another possible reason was that the producercompetitor model corrected yield estimation with additive genotypic effects; the model did not take into account the interaction between adjacent rows. By contrast, height neighbouring covariate used height values measured in each plot, which might be modified by genotypes of the adjacent rows; hence the neighbouring covariate model took into account the part of the interaction between adjacent rows related to height differences. To assess the influence of using plot rather than genotypic values to calculate the covariate, we computed a neighbouring covariate using the genotypic mean heights measured in the 6RP trial (d1HHg computed using height at heading in 1993, d1HMg computed using height at maturity in 1994). The model including d1HHg or $\mathrm{d} 1 \mathrm{HMg}$ is a sub-model of the producer-competitor model. The correlations to the reference trial were only slightly lower than those obtained with the original neighbouring covariate (d1HH in 1993, d1HM in 1994), computed using plot height recorded in SRP $(0.59$ using $\mathrm{d} 1 \mathrm{HHg}$ compared to 0.63 using $\mathrm{d} 1 \mathrm{HH}$ in 1993 and 0.79 using $\mathrm{d} 1 \mathrm{HMg}$ compared to 0.81 using $\mathrm{d} 1 \mathrm{HM}$ in 1994). Thus the lower efficiency of the producercompetitor model seemed to be mainly due to its lack of parsimony. This model appeared not to be adapted to trials with a low number of replications, but may still prove its interest when grouping multilocal or pluriannual trials on the same genotypes as shown by David et al. [7].
The results in Table III show that the use of the reduction of the residual mean squares as the only criterion for comparing the efficiency of the different correction models would have led to false conclusions: the choice of the producer-competitor model instead of neighbouring covariate models, and the evidence of competition due to differences in heading date while this covariate did not improve the correlation with the 6RP trial. Hence, a reference trial seems essential to test the relevance of any new model or any neighbouring covariate based on a new trait, as well as when studying a new species. Nevertheless, there are numerous studies in wheat showing the efficiency of neighbouring covariate based on height in correcting for competition $[10,14,16]$. Therefore, we believe that neighbouring covariate based on height could be used routinely, without reference trial, when it leads to a significant reduction of the residual mean squares.

Figure 1 shows the relationships between 6RP yield and uncorrected SRP yield, SRP yield corrected by the covariate using height at heading and by the producer-competitor model. The variance of the corrected estimation of yield given by the producer-competitor model was greater than that of the covariate adjusted estimation: the producercompetitor model provided larger corrections to SRP yield than the neighbouring covariate. Thus some genotypes were moved away from the bisecting line whereas their adjustment by the covariate model was satisfactory (genotypes 24,27 or 8). On the other hand, some other genotypes were better corrected by the producer-competitor model than by the covariate model (genotypes 38 or 25 ). Though the corrections obtained with the two models seemed to be quite different, the correlation to the reference trial was not improved when combining the covariate approach and the producer-competitor model.

\section{Conclusion}

Covariate adjustment by mean height difference of neighbours was found to be the most efficient 
(1)

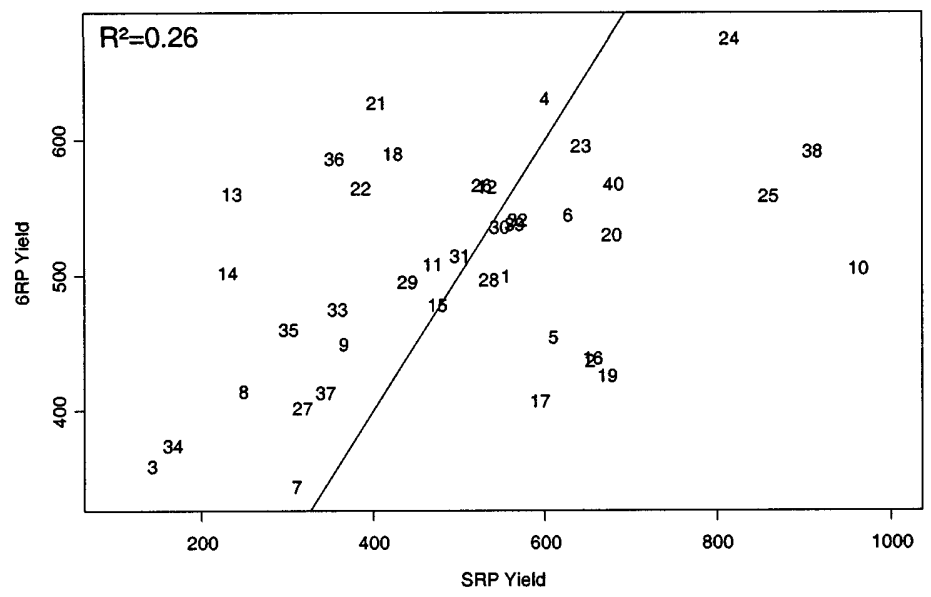

(2)

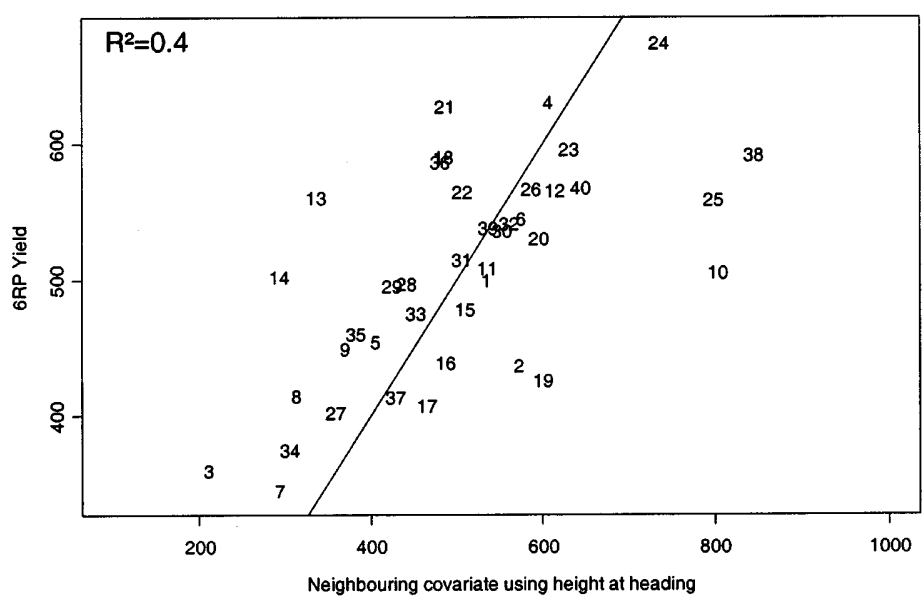

(3)

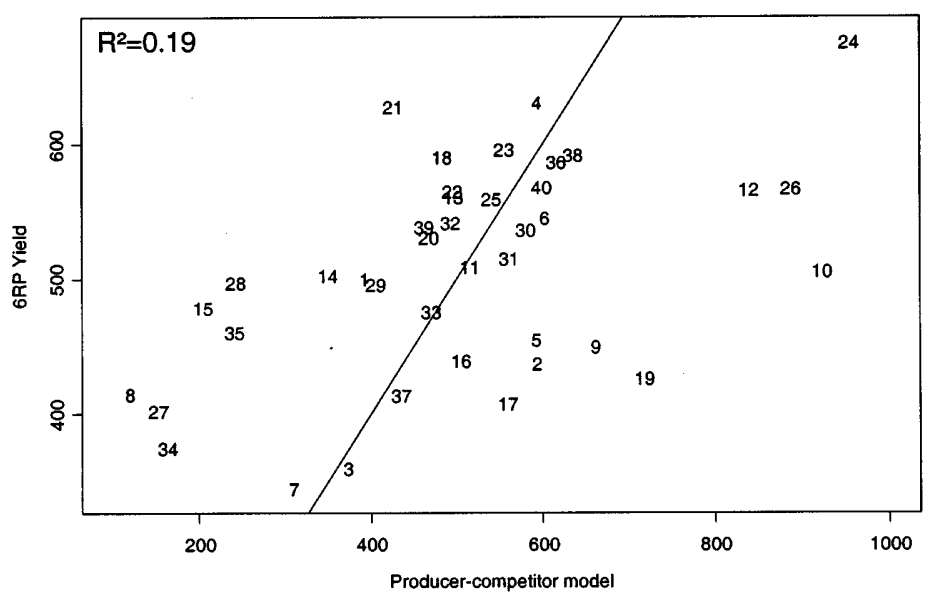

Figure 1. Relations between yield genetic means corrected or not for intergenotypic competition in SRP trial and means in 6RP trial for the 1992-1993 experiment: (1) SRP mean, (2) SRP mean adjusted by the height at heading neighbouring covariate, (3) SRP mean adjusted by the producer-competitor model $\left(\mathrm{g} \cdot \mathrm{m}^{-2}\right)$. 
model to correct interplot competition in SRP trial. In both experiments studied here, as in a previous independent one [10], this adjustment led to a relative selection efficiency of $85 \%$. This criterion is quite important as it shows that the selection of the best lines based on their SRP corrected yield leads to the choice of the highest yielding lines in monoculture with a high probability. The producer-competitor model, though more general than the neighbouring covariate model, is less efficient, probably because of the large number of parameters to be estimated. Moreover, the estimator of pure stand genetic values $(\mathrm{pr}+2 \mathrm{cr})$ estimated from the producer-competitor model are not fully in line with values from trials with larger plots. Indeed, estimating the interference effect of a given genotype on its neighbours based on individuals which might be morphologically very distant from this genotype is not likely to provide the best parameter to construct pure stand value i.e. interference effect on the genotype itself which is the closest possible individual to itself. On the contrary, the producercompetitor model might be useful for characterising genotypes for their behaviour in genetically heterogeneous cultures, such as multiline or crop mixtures.

The test on the differences of correlation coefficients put forward that height measured at heading was more efficient than height measured at maturity in correcting competition effects. However, this result, obtained on a single experiment, needs to be confirmed. The two earliness traits were not efficient. The search for other traits more efficient as a covariate should include the measure of plant height at different stages during the development as done by Kempton et al. [14] in triticale trials. Other traits such as tiller number, leaf number, length and height of the flag leaf have been described as possibly involved in competition phenomena [11, 17]. However, the efficiency of the correction that we obtained here with height at heading or height at maturity is sufficient for the selection in early generations. As height is usually measured in early generation trials, this does not induce extra work and cost. Moreover, the neighbouring covariate model is easy to run.
Acknowledgements: The authors wish to thank N. Galic and M.-T. Marcombe for their technical help in conducting these experiments.

\section{References}

[1] Azaïs J.M., Design of experiments for studying intergenotypic competition, J. Roy. Statist. Soc. Ser. B 49 (1987) 334-345.

[2] Baldy C., Sur le comportement de cultivars de blé tendre cultivés seuls, ou en associations binaires en lignes alternées, Ann. Agron. 25 (1974) 61-69.

[3] Becker W.A., Manual of quantitative genetics, Fourth Edition, Academic enterprises, Pullman, Washington, 1984.

[4] Besag J.E., Kempton R.A., Statistical analysis of field experiments using neighbouring plots, Biometrics 42 (1986) 231-251.

[5] Brabant P., Morin A., Picard E., Mistou M.N., Comparaison de trois dispositifs expérimentaux utilisés pour estimer le rendement chez le blé tendre d'hiver (Triticum aestivum L.), Agronomie 9 (1989) 949-955.

[6] Bradshaw J.E., Competition between cultivars of fodder kale (Brassica oleracea L.) in yield trials with single-row plots, Euphytica 35 (1986) 433-439.

[7] David O., Monod H., Lorgeou J., Philippeau G., Control of interplot interference in grain maize: a multisite comparison, Crop Sci. (in press).

[8] Efron B., Tibshirani R.J., An introduction to the bootstrap, Chapman and Hall, New York, 1982.

[9] Fisher R.A., Are your results confounded by intergenotypic competition?, in: Proceedings of the Vth International Wheat Genetics Symposium, New Delhi, India, 1979, pp. 767-777.

[10] Goldringer I., Brabant P., Kempton R.A., Adjustment for competition between genotypes in single-row-plot trial of winter wheat (Triticum aestivum), Plant Breed. 112 (1994) 294-300.

[11] Hamblin J., Donald C.M., The relationship between plant form, competitive ability and grain yield in a barley cross, Euphytica 23 (1974) 535-542.

[12] Kempton R.A., Adjustment for competition between varieties in plant breeding trials, J. Agric. Sci. Camb. 98 (1982) 599-611.

[13] Kempton R.A., Statistical models for interplot competition, Asp. Appl. Biol. 10 (1985) 110-120. 
[14] Kempton R.A., Gregory R.S., Hughes W.G., Stoehr P.J., The effect of interplot competition on yield assessment in triticale trials, Euphytica 35 (1986) 257-265.

[15] Kramer T., Van Ooijen J.W., Spitters C.J.T., Selection for yield in small plots of spring wheat, Euphytica 31 (1982) 549-564.

[16] Philippeau G., David O., Monod H., Interplot competition in cereal variety trials, in: van Houvelingen H.C. (Ed.), XVIIIth International Biometrics Conference, Amsterdam, The Netherlands, 1996, pp. 107-116.
[17] Powell W., Caligari P.D.S., Goudappel P.H., Thomas W.T.B., Competitive effects in monocultures and mixtures of spring barley (Hordeum vulgare), Theor. Appl. Genet. 71 (1985) 443-450.

[18] Scheffe H., A "mixed model" for the analysis of variance, Ann. Math. Stat. 17 (1959) 23-36.

[19] Scheinberg E., The sampling variance of the correlation coefficients estimated in genetic experiments, Biometrics 22 (1966) 187-191.

[20] Speckel D., Vincourt P., Azais J.M., Kobilinsky A., Étude de la compétition interparcellaire chez le tournesol, Biométr.-Praxim. 27 (1987) 21-43. 